\title{
Air pollution and its health impacts: the changing panorama
}

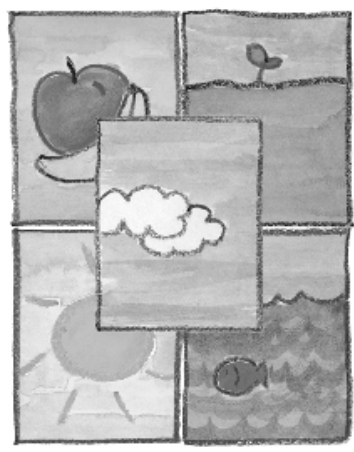

AIR POLLUTION is a major blot on our environmental health scorecard: in some Western countries, it is estimated that car emissions kill twice as many people as car crashes. ${ }^{1}$ In both urban Australia and New Zealand, the main sources of air pollution are motor vehicle emissions, wood smoke from home heating, and industrial pollution. Bushfires are another important source of air pollution in some parts of Australia. In New Zealand, an estimated 900 deaths per year are attributable to air pollution ( $2 \%$ of all deaths), of which nearly half are due to motor vehicle emissions. ${ }^{2}$ If a third of these deaths could be avoided through increased public transport use (and thus reduced car use), improved fuels and pollution-control technology for cars, the "lives saved" would be greater than deaths due to HIV/AIDS, malignant melanoma, or workplace injuries. ${ }^{2}$

The effect of air pollution on health has become a major concern in recent years. In Australia, the increasing interest in this issue has been spurred not so much by a worsening of air quality as by accumulating evidence of its effect on health and the perceived need to "do something about it". Epidemiological research into air pollution over the past 20 years has demonstrated cardiorespiratory health effects ranging from minor respiratory symptoms to increased hospital admissions and mortality. ${ }^{3}$ Toxicological and clinical studies have elucidated the mechanisms for some effects, but the association between relatively low urban air pollution levels and increased cardiorespiratory mortality has not yet been explained.

There is also increasing global awareness of the extreme levels of indoor and outdoor air pollution arising from the use of coal and biomass (eg, wood, farm waste, cowdung) for cooking and heating in developing countries. ${ }^{4}$ Coalburning to fuel industry and produce electricity is another major source of air pollution in some countries - for example, India and China, where cheap coal is an important factor in industrialisation. On top of this, most developing countries have a rapidly worsening problem of motor vehicle traffic congestion and associated air pollution (Box 1). The combination of these factors means that in most large urban areas exposure to air pollution is severe. ${ }^{4}$

National Center for Epidemiology and Population Health, Australian National University, Canberra, ACT.

Tord E Kjellstrom, MedDr, MEng, Professor.

Faculty of Science, University of the Sunshine Coast, Maroochydore, QLD.

Anne Neller, BSc, PhD, Lecturer; Rod W Simpson, BSc, PhD, Dean, and Professor in Environmental Science.

Reprints: Professor Tord E Kjellstrom, National Center for Epidemiology and Population Health, Australian National University, Canberra, ACT. tord.kjellstrom @ anu.edu.au

\section{ABSTRACT}

- Urban air pollution levels are associated with increased mortality and cardiorespiratory morbidity.

- These health effects occur even at exposure levels below those stipulated in current air-quality guidelines, and it is unclear whether a safe threshold exists.

- Air pollution in Australia and New Zealand comes primarily from motor vehicle emissions, electricity generation from fossil fuels, heavy industry, and home heating using wood and coal.

- In individual patients a direct link between symptoms and air pollution exposure may be difficult to establish and may not change their clinical management. However, avoiding exposure during periods of peak pollution may be beneficial.

- Although there is some evidence that urban air pollution in Australia and New Zealand has been decreasing (through reduced car use, improved emission-control technology and use of more energy-efficient devices in the household and in industry), pollution levels are still unsatisfactory.

Further reductions may prevent hundreds of cardiorespiratory hospital admissions and deaths each year.

MJA 2002; 177: 604-608

\section{Major air pollutants}

The sources, health effects and vulnerable groups for major air pollutants are summarised in Box 2. In typical urban air pollution situations, particulate matter (PM) and gaseous pollutants (oxides of nitrogen $\left[\mathrm{NO}_{\mathrm{x}}\right]$, ozone, carbon monoxide [CO] and "air toxics" [eg, hydrocarbons, aldehydes]) occur together, as the sources are the same. Furthermore, levels of pollutants vary dramatically by location and over time, depending on changing meteorological factors such as wind speed and wind direction. This makes it very difficult to isolate the health effects of individual pollutants. It is more useful to consider each of the major pollutants as "indicators" of the mixture of air pollution created by motor vehicles, home heating and industry. Continuous monitoring of PM, $\mathrm{NO}_{\mathrm{x}}$, ozone and $\mathrm{CO}$ has been established in recent years in the major Australian cities, ${ }^{6}$ but these data provide only general estimates of actual exposures in individuals. $\mathrm{CO}$ is the only major air pollutant for which a biomarker of exposure (carboxyhaemoglobin in erythrocytes) is currently available. 
Researchers are currently investigating the importance of the size and chemical composition of particles as a causal factor for cardiorespiratory effects. ${ }^{3}$ Focus has now shifted to the very small particles, $\mathrm{PM}_{2.5}$ and $\mathrm{PM}_{1}$ (ie, particles smaller than $2.5 \mu \mathrm{m}$ or $1 \mu \mathrm{m}$, respectively). ${ }^{3}$ As very small particles penetrate further into the lungs than larger particles, they are believed to be more strongly associated with adverse health effects. Diesel engine emissions contribute disproportionately to the verysmall-particle fraction of urban air pollution. ${ }^{7}$

The recent documentation of lung cancer as an effect of longterm exposure to urban air pollution ${ }^{8}$ puts the spotlight on carcinogenic chemicals in the smallest air particles and on carcinogenic gases (eg, benzene; benzo(alpha)pyrene) as possible causal agents.

Carbon dioxide $\left(\mathrm{CO}_{2}\right)$, another air pollutant created by fuel combustion, has no direct health effects

\section{1: Manila morning, March 2001}

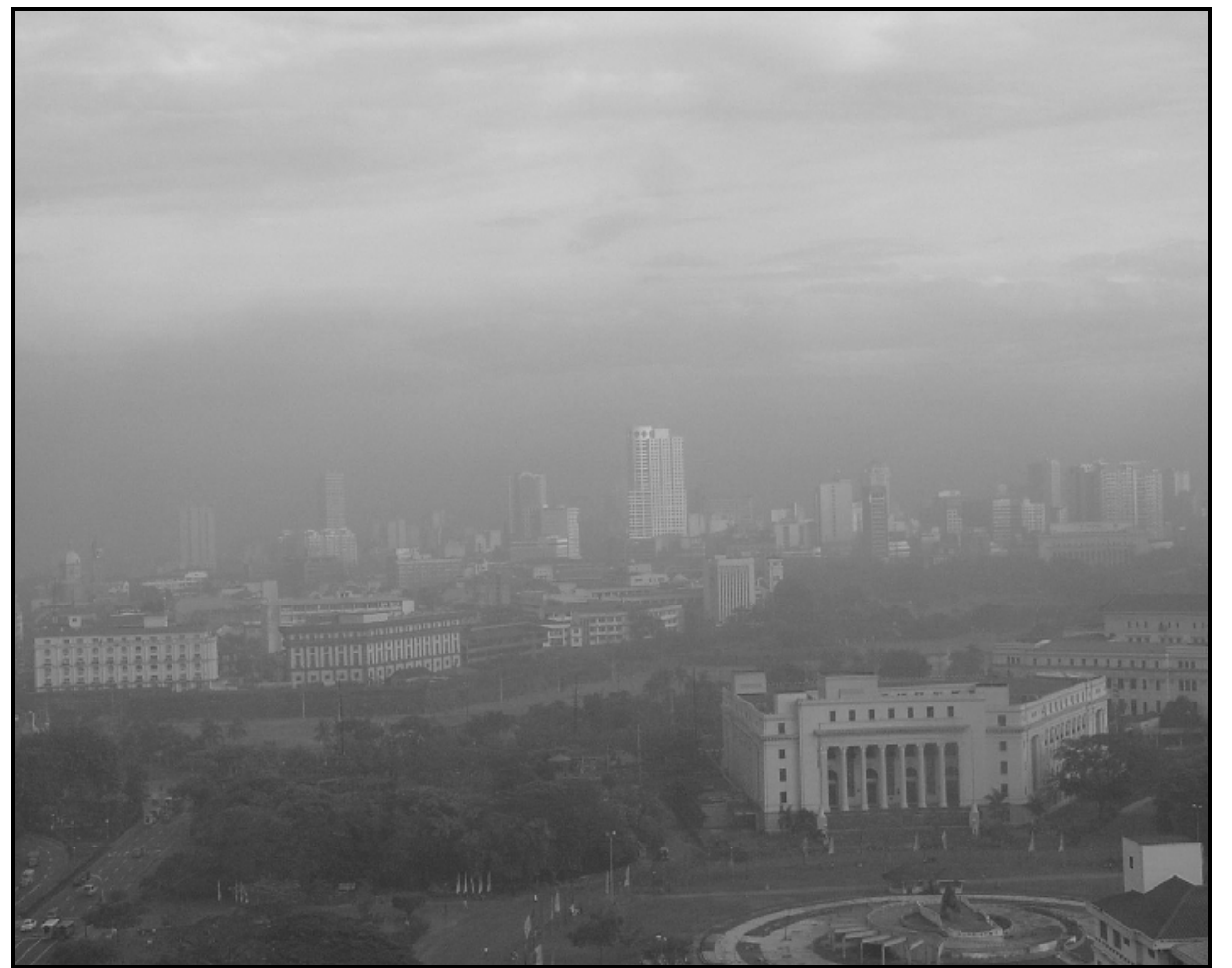

Motor vehicle emissions in large urban areas of developing countries are a growing problem.

\section{2: Selected outdoor air pollutants and their effects on health*}

\section{Pollutant group (source)}

Particulate matter (biomass and fossil fuel Upper respiratory tract irritation and infection; combustion in home heating, industry and exacerbation of and increased mortality from motor vehicle engines; cigarette smoke) cardiorespiratory diseases

\section{Sulfur dioxide and acid aerosols (fossil}

fuel combustion; metal smelting and

petrochemical industries; home heating/

cooking with coal)

Oxides of nitrogen (fuel combustion at high temperature [eg, from vehicle engines, gas cooking and heating])

Ozone (reaction product of sunlight and vehicle pollutants; hydrocarbons and oxides of nitrogen)

Carbon monoxide (biomass and fossil fuel combustion; cigarette smoke and vehicle exhaust)

Lead (smelting; leaded petrol [now banned in Australia])

Other pollutants; "air toxics" (hydrocarbons, aldehydes, other organic compounds, asbestos) cardiorespiratory diseases, including asthma

Eye irritation; upper respiratory tract infection (especially in children); exacerbation of asthma irritation of bronchi

Eye and throat irritation; reduced exercise capacity; exacerbation of respiratory disease

Headache, nausea, dizziness, breathlessness, fatigue, visual disturbance, confusion; angina, coma, death; low birthweight (after maternal exposure during pregnancy)

In children: neuropsychological and cognitive effects. In adults: hypertension, classic lead poisoning

Eye irritation; lung cancer; asthma
Throat irritation; exacerbation of
Contributing or

potentiating factors/ Populations especially agents

Sulfur dioxide, sulfuric acid; cold, heat, humidity

Exercise, particulates, asthma

\section{vulnerable}

Elderly people with respiratory and cardiovascular diseases; children with asthma

People with respiratory diseases (eg, children with asthma); elderly people with respiratory and cardiovascular diseases

Exercise, respiratory People with respiratory diseases tract infection, (eg, children with asthma) asthma

Exercise, respiratory People with respiratory tract infection, diseases (eg, children asthma with asthma)

Coronary artery disease

People with ischaemic heart disease

Other sources of Children, lead; iron deficiency pregnant women

Smoking, occupational exposures
Smokers, asbestos workers, people with asthma, children

* Adapted from World Health Organization air quality guidelines. ${ }^{5}$ 


\section{3: Adverse respiratory health effects of air pollution $^{10}$}

- Increased mortality.

- Increased incidence of lung cancer.

- Increased frequency of symptomatic asthma attacks.

- Increased incidence of lower respiratory tract infections.

- Increased exacerbation of chronic cardiopulmonary or other diseases, reflected in various ways, including reduced ability to cope with daily activities, increased hospitalisation, increased physician visits and medication, and decreased pulmonary function.

- Reduction of FEV 1 or FVC associated with clinical symptoms

- Increased prevalence of wheezing unrelated to colds, or wheezing on most days or nights.

- Increased prevalence or incidence of chest tightness.

- Increased prevalence or incidence of cough/phlegm production requiring medical attention.

- Increased incidence of acute upper respiratory tract infections that interfere with normal activity.

- Acute upper respiratory tract infections that do not interfere with normal activity.

- Eye, nose and throat irritation that may interfere with normal activities (eg, driving a car), if severe.

$\mathrm{FEV}_{1}=$ forced expiratory volume in one second. FVC = forced vital capacity.

at the concentrations occurring in the ambient environment. However, it is the main "greenhouse gas" causing global climate change ${ }^{9}$ and, as such, indirectly contributes to the global health impact of such change. Australia and New Zealand are among the few countries where vehicle-related $\mathrm{CO}_{2}$ emissions have substantially increased since 1996, when the Kyoto Protocol on greenhouse gas reductions was signed. Efforts to reduce urban air pollution by reducing the use of cars would have the added benefit of reducing $\mathrm{CO}_{2}$ emissions.

\section{Adverse health effects}

There is an exhaustive literature on the health effects of the major air pollutants, including numerous epidemiological and toxicological studies. In a recent review, ${ }^{10}$ the American Thoracic Society (ATS) expanded its list of adverse health effects of air pollution to include not only clinical outcomes (such as hospital admissions, loss of lung function, and mortality) (Box 2), but also diminished quality of life and subclinical symptoms that may interfere with daily activities (Box 3). In any particular study, establishing whether there is an association between air pollution and one or more of the effects listed in Box 2 and Box 3 depends on exposure level, the background health status of the population exposed, and their age. Thus, some of the evidence may appear conflicting, and the ATS recommends that the effects in Box 3 should be included in future studies. ${ }^{10} \mathrm{We}$ describe here the key epidemiological findings on the major effects of air pollution.

\section{Mortality}

Most recent epidemiological studies of air pollution and mortality have used time-series analysis to relate daily mortality rates to daily air pollution levels (on the same day or previous days). However, this approach cannot be used to ascertain whether increased mortality reflects a significant reduction in life expectancy. ${ }^{3}$

A few studies have documented associations between mortality and air pollution exposure over longer periods. The Harvard "six cities" study ${ }^{11}$ involved a 14-16-year prospective cohort of more than 8000 adults in the United States, and the American Cancer Society (ACS) study collected data on over 500000 people living in 51 different US metropolitan areas from 1982 to $2000 .^{8,12}$ These studies reported significant associations between annual average particle pollution levels $\left(\mathrm{PM}_{10}\right.$ or $\left.\mathrm{PM}_{2.5}\right)$ and annual allcause mortality rates: an average increase of $10 \mu \mathrm{g} / \mathrm{m}^{3}$ of $\mathrm{PM}_{10}$ or $\mathrm{PM}_{2.5}$ was associated with a $3 \%-4 \%$ increase in mortality. The ACS study also found a significant association between levels of $\mathrm{PM}_{2.5}$ and deaths due to cardiorespiratory diseases and lung cancer. ${ }^{8}$

A "natural intervention" study with long-term exposure and effect data analysed mortality in Dublin before and after coal-burning was banned in $1990 .{ }^{13}$ The annual average particle pollution level declined by $36 \%$ after the ban, while adjusted mortality rates decreased by $15.5 \%$ and $10.3 \%$ for respiratory and cardiovascular deaths, respectively.

No long-term exposure studies have been carried out in Australia or New Zealand, but short-term time-series analy-

\section{4: Levels of particulate matter (PM) and nitrogen dioxide $\left(\mathrm{NO}_{2}\right)$ in air, Port Phillip region (just south of Melbourne central business district), Victoria*}
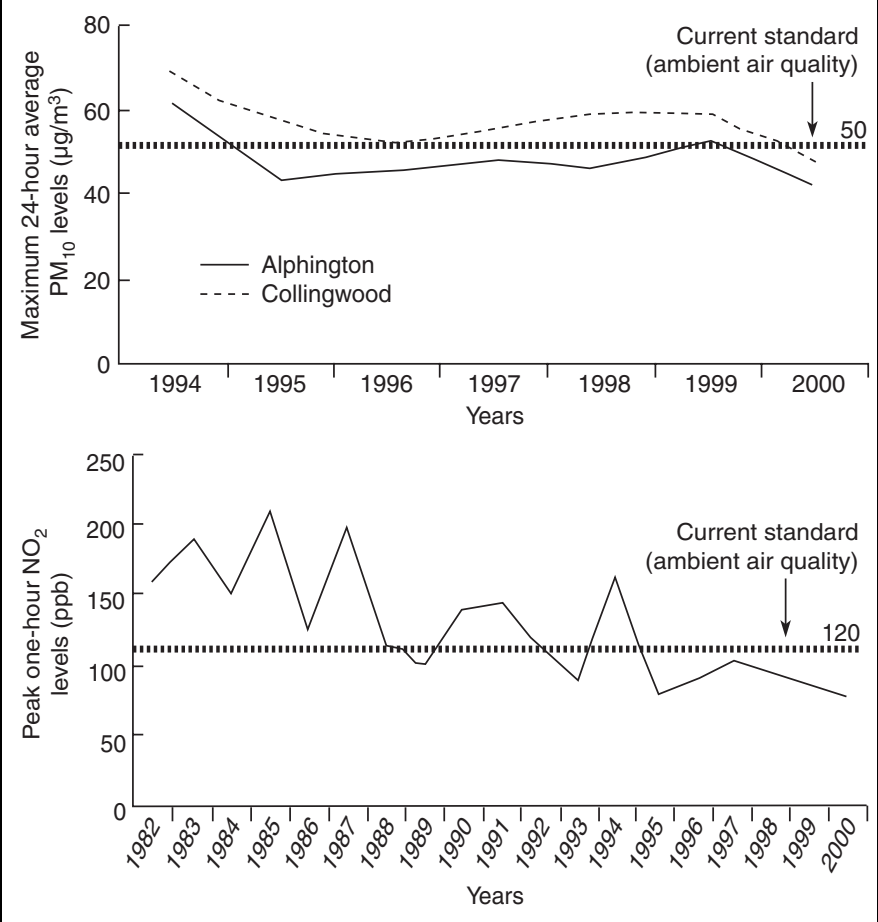

* Source: Victorian Auditor-General's Office. Managing Victoria's air quality, Melbourne, June 2002, pp. 131 and 135 at

<http://www.audit.vic.gov.au/reports_par/air_report.pdf>. 
ses suggest that the situation here is similar to that observed in many US and European studies. Significant associations between daily $\mathrm{PM}_{10}, \mathrm{NO}_{\mathrm{x}}$ and/or $\mathrm{CO}$ levels and daily cardiorespiratory mortality have been found in Sydney, ${ }^{14}$ Brisbane, ${ }^{15}$ and Christchurch, ${ }^{16}$ but the associations have been weaker in Melbourne ${ }^{17}$ and Perth. ${ }^{18}$

A review of epidemiological studies concluded that there may be a relationship between acute ozone exposure and increased mortality, ${ }^{19}$ especially in elderly people. However, the concurrence of high ozone levels with hot weather makes it difficult to separate the effect of heat from the effect of ozone on mortality. In Australia, ozone levels have been found to affect daily mortality rates in Sydney, Brisbane and Melbourne, ${ }^{15,17}$ but the interpretation of these results raises similar concerns to those of the recent review. ${ }^{19}$

\section{Hospital admissions}

Acute time-series studies ${ }^{3}$ have shown associations between particle pollution and daily hospital admissions, mainly for respiratory disease (especially asthma and chronic obstructive pulmonary disease) but also for cardiovascular diseases. ${ }^{18,20-23}$

\section{Other effects}

Studies in Australia have reported an association between particle exposure from dust storms and exacerbation of asthma symptoms, ${ }^{24}$ and between particle exposure and decreased lung function in people with asthma. ${ }^{25}$

Some studies have suggested that air pollutants are related to respiratory allergic diseases by the interaction between pollen allergens and air pollutants: air pollutants adhering to pollen grains may increase their impact, and probably also heighten airway responsiveness to aeroallergens. ${ }^{26}$

\section{Role of the clinician}

Decisions about patient management would not normally be influenced by the patient's exposure to air pollution. (The causal role of air pollution in disease is an epidemiological diagnosis.) However, the following advice may be appropriate for patients who are particularly at risk (eg, those with severe cardiac or respiratory disease):

- Avoid specific exposure situations (such as walking along a highly polluted road) if these appear to exacerbate symptoms;

- Avoid outdoor activities during smog episodes, particularly exercise in the afternoons, when ozone levels are highest $^{27}$ (as a result of delayed interaction between sunlight and morning peak-hour motor vehicle emissions);

- (For patients with asthma) self-monitor peak expiratory flow more frequently during smog episodes and adjust medication if necessary; ${ }^{27}$

- Avoid exposures to extreme heat or cold, as these can further exacerbate the health effects of air pollution;

- Stop smoking, as this further exacerbates the risk of cardiorespiratory diseases.

\section{5: Reflections and predictions}

\section{Circa 1900}

- Cities being rapidly industrialised. Large amounts of sulfur dioxide and particulates being emitted in heavily populated areas from inefficient combustion of coal in power stations and industrial and domestic furnaces.

- Air pollution and resultant lack of sunshine in industrialised areas causing widespread lung damage, high mortality, and an upsurge in diseases such as ricketts in children. Indoor air pollution, from cooking with coal and wood, even worse for health than outdoor pollution

\section{Circa 2100 (a pessimistic view)}

- Increasing air pollution in developing countries.

- Limited progress on motor vehicle emissions in developed countries.

\section{Circa 2100 (an optimistic view)}

- Intelligent global stewardship of our natural resources has led to a major shift towards alternative energy sources such as wind power, solar energy, and fuel-cell engines for vehicles.

- More wood burning to heat houses, as this creates less greenhouse gas emissions than fossil fuel.

- Coal burning in superefficient and clean-burning electric power stations is still continuing in countries with large coal reserves (eg, China, India, the United States).

- Many governments have put pressure on motor vehicle manufacturers to produce less-polluting cars.

- High-quality public transport systems and advanced telecommunications systems have made daily commuting in private cars largely obsolete. Private vehicles are mainly used for leisure activities.

\section{The shifting panorama}

Current levels of major air pollutants in Australian capital cities and New Zealand only occasionally exceed air quality guidelines. Particle pollution levels have remained relatively stable during recent years, while $\mathrm{NO}_{2}$ levels are only slowly declining (Box 4), as the increasing number of vehicles and kilometres driven have been mitigated by increasing use of catalytic converters (for vehicle emission reduction) and improved-quality diesel fuel.

However, the epidemiological evidence shows that air pollution, even at levels below the commonly used air quality guidelines, ${ }^{3,8,11}$ increases mortality rates. ${ }^{2}$ To reduce the burden of disease related to air pollution, Australian and New Zealand governments could choose from a range of policy options that would make the air cleaner in the long term - for example, providing support and infrastructure for increased use of public transport, walking and bicycling; popularising new vehicles with low-pollution engines; and encouraging improved efficiency of household heating and cooling devices.

From a global perspective, many developing countries are at a similar stage of industrial and urban development to Western countries 50-80 years ago, when high levels of ambient air pollution from coal-burning were common. At the household level in developing countries, promoting energy-efficient and less-polluting cooking stoves constructed from local materials would be an important step in reducing air pollution. Switching the energy source for cooking to less-polluting kerosene, gas and electricity is 


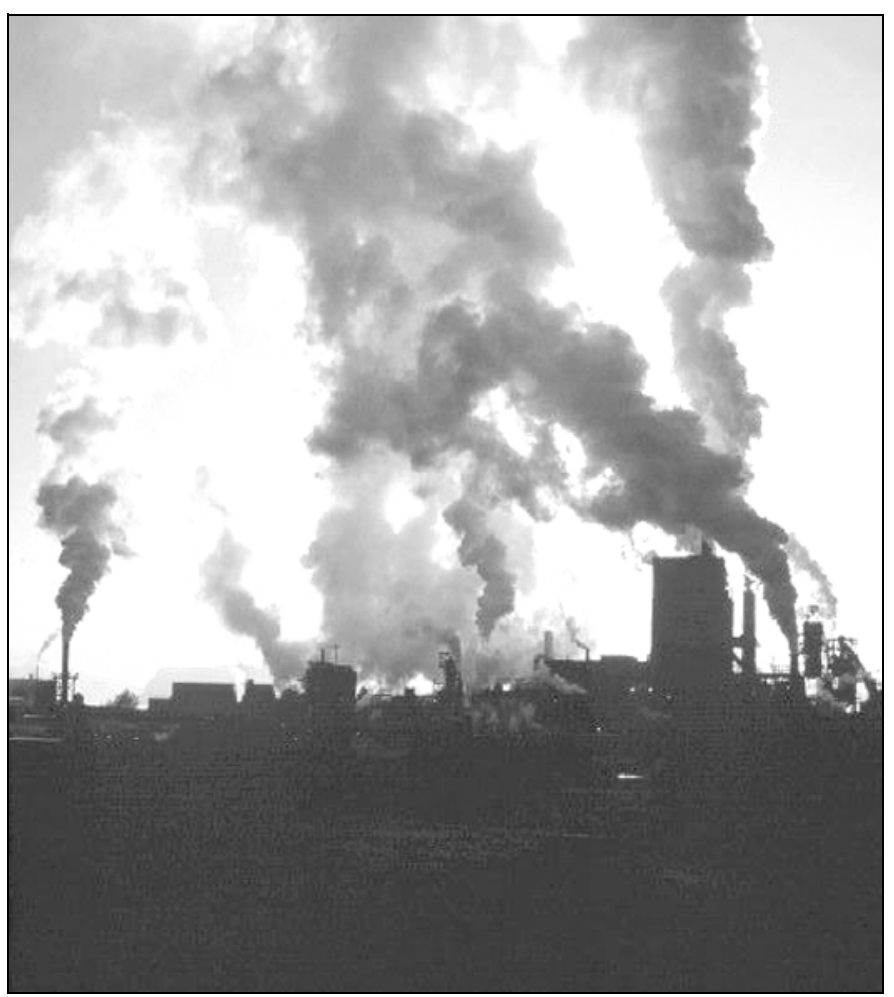

another solution, often out of reach for poor communities in the short term.

Worldwide, a major change in priorities is needed to steer economic development towards low-pollution policies (Box 5).

\section{Competing interests}

None identified.

\section{Acknowledgement}

The funding for TEK's input into this article came from the Burnett Award to Professor A J McMichael, NCEPH, Australian National University.

\section{References}

1. Kunzli N, Kaiser R, Medina S, et al. Public-health impact of outdoor and trafficrelated air pollution: a European assessment. Lancet 2000; 356: 795-801.

2. Fisher G, Rolfe KA, Kjellstrom T, et al. Health effects due to motor vehicle air pollution in New Zealand. Wellington: Ministry of Transport, 2002.

3. Brunekreef B, Holgate ST. Air pollution and health. Lancet 2002; 360: 1233-1242.

4. Health and environment in sustainable development. Geneva: World Health Organization, 1997. (WHO/EHG/97.8.)

5. Air quality guidelines for Europe. Updated version. Geneva: World Health Organization, 2001

6. Simpson R, Williams G, Petroeschevsky A, et al. The assessment of the impact of air pollution on daily mortality and morbidity in Australian cities: description of a study. Environmental Health 2001; 1: 13-17.

7. Diesel fuel and exhausts emissions. Environmental health criteria No 171 Geneva: World Health Organization, 1996

8. Pope C, Burnett R, Thun M, et al. Lung cancer, cardiopulmonary mortality, and long-term exposure to fine particulate air pollution. JAMA 2002; 287: 1132-1141.

9. McMichael AJ, Haines A, Sloof R, et al. Climate change and human health. Geneva: World Health Organization, 1996.

10. What constitutes an adverse health effect of air pollution? Official statement of the American Thoracic Society. Am J Respir Crit Care Med 2000; 161: 665-673.
11. Dockery DW, Pope CA III, Xu X, et al. An association between air pollution and mortality in six U.S. cities. N Engl J Med 1993; 329: 1753-1759.

12. Pope CA III. Thun MJ, Namboodiri MM, et al. Particulate air pollution as a predictor of mortality in a prospective study of U.S. adults. Am J Respir Crit Care Med 1995; 151: 669-674.

13. Clancy L, Goodman P, Sinclair H, Dockery DW. Effect of air-pollution control on death rates in Dublin, Ireland: an intervention study. Lancet 2002; 360: 12101214

14. Morgan G, Corbett S, Wlodarczyk J, Lewis P. Air pollution and daily mortality in Sydney, Australia, 1989 through 1993. Am J Public Health 1998; 88: 759-764.

15. Simpson RW, Williams G, Petroeschevsky A. Associations between outdoor air pollution and daily mortality in Brisbane, Australia. Arch Environ Health 1997; 52 : 442-422.

16. Hales S, Salmond C, Town I, et al. Daily mortality in relation to weather and air pollution in Christchurch, New Zealand. Aust N Z J Public Health 2000; 24: 89-91.

17. Simpson R, Denison L, Petroeschevsky A, et al. Effects of ambient particle pollution on daily mortality in Melbourne, 1991-1996. J Expo Anal Environ Epidemiol 2000; 10: 488-496.

18. Hinwood A. Time series research on health and air pollution in Perth, Western Australia. In: Western Australian Department of Environmental Protection. Technical report. In press; 2002

19. Thurston GD, Ito K. Epidemiological studies of acute ozone exposures and mortality. J Expo Anal Environ Epidemiol 2001; 11: 286-294.

20. Petroeschevsky A, Simpson RW, Thalib L, Rutherford S. Associations between outdoor air pollution and hospital admissions in Brisbane, Australia. Arch Environ Health 2001; 56: 37-52.

21. Morgan G, Corbett S, Wlodarczyk J. Air pollution and hospital admissions in Sydney, Australia, 1990 to 1994. Am J Public Health 1998; 88: 1761-1766.

22. Denison L, Simpson R, Petroeschevsky A, et al. Ambient air pollution and daily hospital admissions in Melbourne 1994-1997. Melbourne: EPA Victoria, 2001 (Report No. 789.)

23. McGowan J. Hider P. Chacko E Town G. Particulate air pollution and hospita admissions in Christchurch, New Zealand. Aust N Z J Public Health 2000; 26: 23 29

24. Rutherford S, Clark E, McTainsh G et al. Characteristics of rural dust events shown to impact on asthma severity in Brisbane, Australia. Int J Biometeorol 1999; 42: 217-212.

25. Rutherford S, Simpson R, Williams G, et al. Relationships between environmental factors and lung function of asthmatic subjects in South East Queensland, Australia. J Occup Environ Med 2000; 42: 882-891.

26. Glikson M, Rutherford S, Simpson R, et al. The microscopic and submicron components of atmospheric particulates occurring during high asthma periods in Brisbane, Queensland, Australia. Atmospheric Environment 1995; 29: 549 562.

27. Abelsohn A, Stieb D, Sanborn, MD, Weir E. Identifying and managing adverse environmental health effects: 2. Outdoor air pollution. CMAJ 2002; 166: 1161 1167.

(Received 5 Aug, accepted 8 Nov 2002)

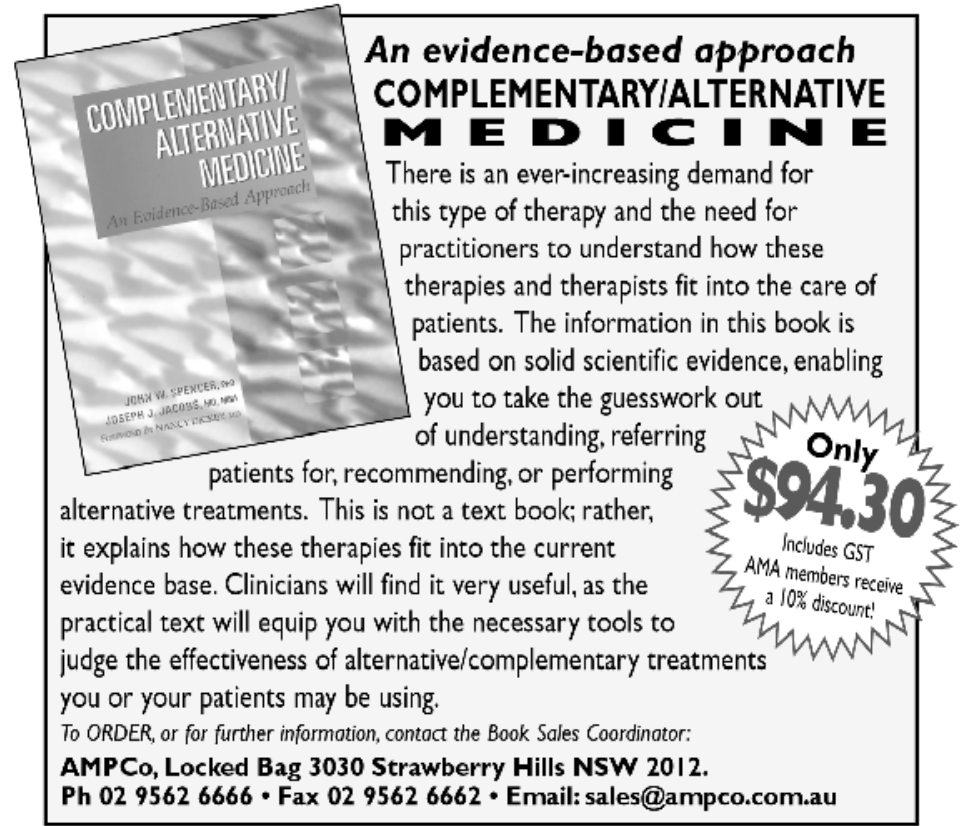

AMPCo, Locked Bag 3030 Strawberry Hills NSW 2012

Ph 0295626666 •Fax 0295626662 •Email: sales@ampco.com.au 